\title{
Multichannel Intraluminal Impedance and pH-Metry for Investigation of Symptomatic Gastroesophageal Reflux Disease
}

\author{
J.Weigt K. Mönkemüller U.Peitz P. Malfertheiner \\ Department of Gastroenterology, Hepatology and Infectious Diseases, Otto von Guericke University Magdeburg, \\ Magdeburg, Germany
}

\section{Key Words}

Multichannel intraluminal impedance $\cdot \mathrm{MII}-\mathrm{pH} \cdot$

Impedance $\cdot$ Reflux monitoring $\cdot$ Nonacid reflux $\cdot$ Reflux disease questionnaire $\cdot$ Gastroesophageal reflux disease ly to be associated with atypical symptoms. Conclusions: These data show that nonacid reflux can be associated with symptoms in patients with GERD symptoms. The diagnostic value of MII-pH is independent of PPI therapy.

Copyright $\odot 2007$ S. Karger AG, Basel

\section{Introduction}

Combined multichannel intraluminal impedance and $\mathrm{pH}$-metry (MII-pH) is a technique that enables monitoring of gastroesophageal reflux independent of its acidity, and therefore is suitable for investigation of symptomatic patients on and off PPI therapy [1]. MII-pH detects the presence of a bolus by means of changes in the conduction between electrodes placed in the esophagus [2]. Bolus contents as liquids and mixed contents have a low impedance, whereas gas contents have a higher impedance than the threshold in the esophagus. By using several pairs of electrodes, the detection of bolus movement is possible. The reflux is categorized as acid or nonacid by combination with pH-metry. A retrograde bolus movement with simultaneous decrease in esophageal $\mathrm{pH}$ would be categorized as an acid reflux. Without the $\mathrm{pH}$ fall the reflux episode would be a nonacid one [3]. The basic principles of this method are illustrated in figure 1.

\section{KARGER}

Fax +4161306 1234

E-Mail karger@karger.ch

www.karger.com
(C) 2007 S. Karger AG, Basel

0257-2753/07/0253-0179\$23.50/0

Accessible online at:

www.karger.com/ddi
Jochen Weigt

Department of Gastroenterology, Hepatology and Infectious Diseases

Otto von Guericke University Magdeburg, Leipziger Strasse 44

DE-39120 Magdeburg (Germany)

E-Mail jochen.weigt@medizin.uni-magdeburg.de 
Fig. 1. Basic technical issues of MII-pH. a Configuration of electrodes on the catheter. The pH electrode at $5 \mathrm{~cm}$ helps to classify the reflux as acid or nonacid. b Typical appearance of a wet swallow. The fall in intraluminal impedance is first detected orally and then propagates distally through the esophagus body towards the stomach (arrow). The initial increase of impedance $[R]$ is due to swallowed air that encircles the bolus. c A reflux episode is plotted. The fall in intraluminal impedance is first detected in the very distal channel and than propagates orally. After reaching its maximum proximal extent, the bolus (refluxate) moves back (arrows) towards the stomach.

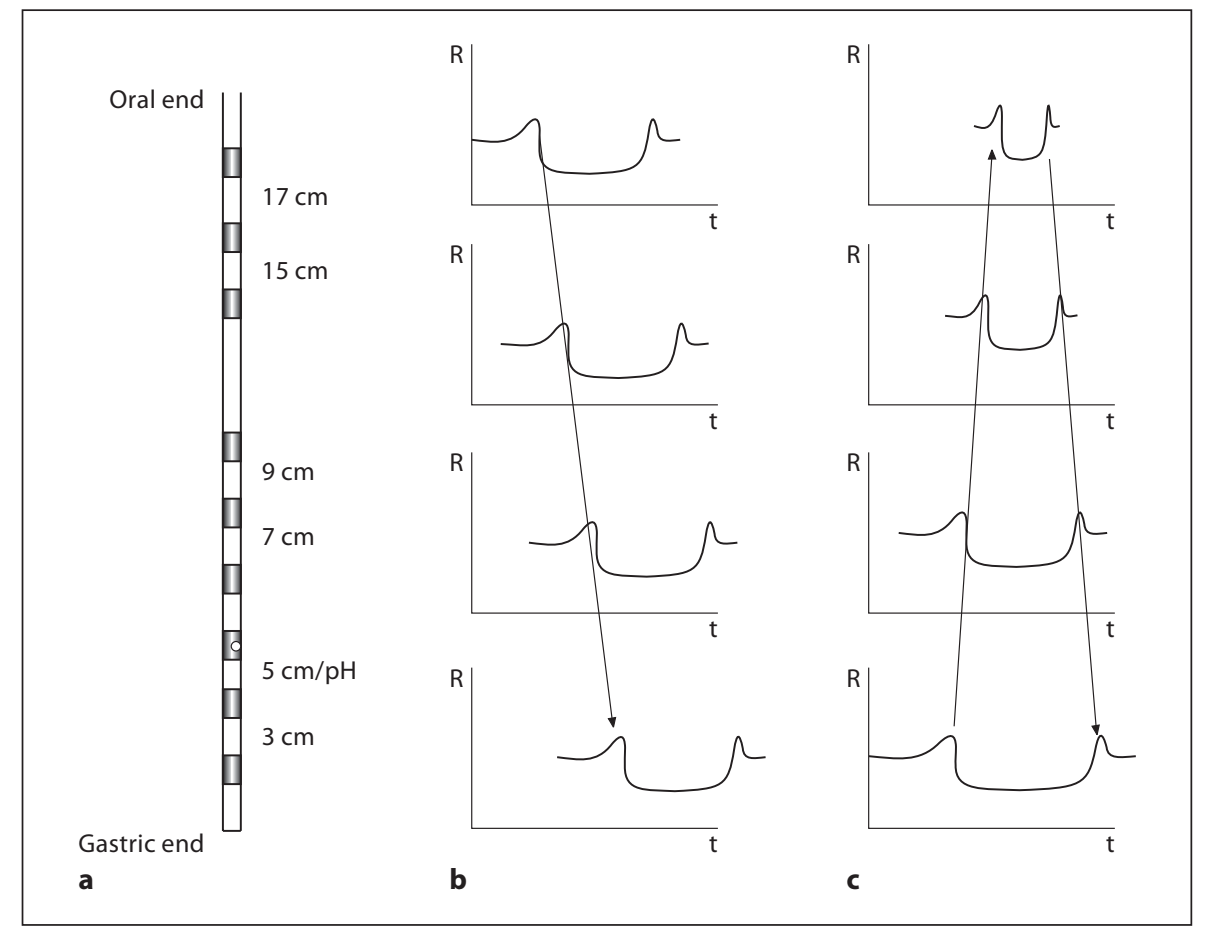

Recent studies showed that symptoms in patients with acid-suppressive therapy are often associated with nonacid reflux [4].

\section{Aims}

To investigate the utility of MII-pH in the clinical investigation of patients with symptoms of gastroesophageal reflux disease (GERD) and to compare patients taking PPI with patients without acid-suppressive medication.

\section{Patients and Methods}

Patients with GERD symptoms were investigated. Symptoms were defined as typical (heartburn, regurgitation and chest pain) and atypical (upper abdominal pain, coughing, sore throat, globus, pressure, burning of the tongue). PPI therapy was not stopped during the investigation. Patients presented after an overnight fasting period. Before MII-pH monitoring we performed esophageal manometry in each patient to rule out motility disorders and to label the distance between the lower esophageal sphincter (LES) and the nostril for defining the depth of insertion of the MII-pH probe. Immediately after the manometry the impedance catheter (Sandhill Scientific Inc.) was inserted. The $\mathrm{pH}$ electrode was placed $5 \mathrm{~cm}$ above the LES and the impedance channels were located at 3, 5, 7, 9, 15 and $17 \mathrm{~cm}$ above the LES. Data were sampled stored in a portable recorder (Sleuth ${ }^{\circledR}$, Sandhill Scientific Inc.). The patients were advised on the use of the recorder and instructed to keep a detailed diary report in addition to the electronic data sheet recording documenting body position, meal intake, medication and symptoms. The MII-pH recording lasted over a period of $24 \mathrm{~h}$.

The data were analyzed using the BioView Analysis ${ }^{\circledR}$ program software tool from Sandhill Scientific Inc. In addition, all records were also analyzed manually to obtain the highest detection rate of reflux episodes. Meal periods were excluded from the analysis. The analysis of symptoms was made by relationship to reflux, either acid- or nonacid-related, all reflux-related and not related to any kind of reflux. We also used the symptom index (SI) as a classification of overall association of reflux symptoms. SI is defined as the percentage of symptom-associated reflux from all detected reflux episodes. A SI $\geq 50 \%$ was defined as positive $\left(\mathrm{SI}^{+}\right)$.

All patients were asked to perform the Reflux Disease Questionnaire (RDQ; German version) [5] on the day of MII-pH performance. This short questionnaire contains 12 items regarding heartburn and regurgitation as well as dyspepsia symptoms. A good correlation of RDQ score and presence of GERD has been shown [5].

\section{Statistical Analysis}

Data were analyzed using Microcal Origin ${ }^{\circledR}$ statistical software. For comparison of the symptoms and their association to reflux, the $\chi^{2}$ test was used. $\mathrm{p}<0.05$ was considered to be significant. 
Table 1. Findings and results of MII-pH in patients on PPI therapy $\left(\mathrm{PPI}^{+}\right)$and without PPI medication $\left(\mathrm{PPI}^{-}\right)$

\begin{tabular}{lcc}
\hline & PPI $^{+}$ & PPI $^{-}$ \\
\hline Mean acid exposure $\mathrm{pH}<4, \%$ & $7.35 \pm 11.37$ & $11.39 \pm 17.92$ \\
Composite score $>14.9^{1}$ & $5 / 16$ & $6 / 16$ \\
Mean acid clearance time, s & $96.9 \pm 92.6$ & $118.3 \pm 126.4$ \\
Mean bolus clearance time, s & $15 \pm 6$ & $12.2 \pm 4.6$ \\
Mean acid reflux episodes & $40.3 \pm 45.7$ & $49.4 \pm 60.3$ \\
Mean nonacid reflux episodes & $84 \pm 76.8$ & $50.7 \pm 35.4$ \\
Reported symptoms & 560 & 698 \\
Symptom correlation to acid reflux & $33 \%$ & $25 \%$ \\
Symptom correlation to nonacid reflux & $21 \%$ & $36 \%$ \\
Symptom index positive for atypical symptoms & $63.2 \%(12 / 19)$ & $33.3 \%(7 / 21)$ \\
Symptom index positive for typical symptoms & $36.8 \%(7 / 19)$ & $66.6 \%(14 / 21)$ \\
\hline \multicolumn{2}{c}{${ }^{1}$ Clinical definition of GERD. } & \\
\hline
\end{tabular}

\section{Results}

We investigated 32 patients (16 male, 16 female) with symptoms of reflux disease. Mean age was 53.5 years (range 19-74). 16 patients were on PPI therapy $\left(\mathrm{PPI}^{+}\right)$and 16 patients were not taking any acid-suppressive medication $\left(\mathrm{PPI}^{-}\right)$. Detailed results of the MII-pH recordings are summarized in table 1 . The mean study duration was $22 \mathrm{~h} 57 \mathrm{~min}$ (range from $17 \mathrm{~h} 02 \mathrm{~min}$ to $44 \mathrm{~h} 23 \mathrm{~min}$ ).

A total of 3,591 reflux episodes were recorded. Reflux was more common in the upright position (3,014 episodes) than in the recumbent position (577 episodes). A total of 1,258 symptoms were reported (560 in the $\mathrm{PPI}^{+}$ group and 698 in the PPI group). While the overall relation of symptoms to reflux was comparable in both groups, the relation of symptoms to acid reflux was higher in the $\mathrm{PPI}^{+}$group (33 vs. $25 \%$ ) and the relation of symptoms to nonacid reflux was higher in the $\mathrm{PPI}^{-}$group (36 vs. $21 \%$ ). Regarding reflux acidity, there was more acid reflux in patients off PPI (49.4 episodes) than on PPI (40.3 episodes). Nonacid reflux is more common in patients taking PPI medication (mean 84 episodes) than without PPI (mean 50.7 episodes). A part of $67 \%$ of all reflux episodes in the PPI group had a nonacid content, while in the off PPI group the fraction of nonacid reflux was $51 \%$. The number of reflux episodes that reach up to $15 \mathrm{~cm}$ above the LES were similar in both groups (on PPI 37; off PPI 33).

Discriminating the two groups of patients, there was no association between the type of symptom and the association to reflux in the $\mathrm{PPI}^{+}$group. In the patients taking no PPI, the association between type of symptom and the association to reflux was highly significant $(\mathrm{p}<0.001)$.
In the $\mathrm{PPI}^{-}$group the association to reflux is more likely to show typical symptoms, whereas atypical symptoms are less associated to reflux. In the $\mathrm{PPI}^{+}$group a positive SI was found more often in combination with atypical symptoms (13 times) than with typical symptoms (6 times). SI was more often positive regarding nonacid reflux (12 times) than acid reflux (4 times). In the $\mathrm{PPI}^{-}$ group a positive SI was found mostly in combination with typical symptoms (13 times; atypical 7 times). Regarding the acidity of reflux there was no difference.

Analysis whether the typical or atypical symptoms are associated to reflux (positive or negative SI) show that most reported symptoms have a positive SI (40 positive; 26 negative). In addition, there is a difference between typical $\mathrm{SI}^{+}$and atypical $\mathrm{SI}^{+}$. On PPI the atypical $\mathrm{SI}^{+}$rate is higher (12/19) than the typical SI+ rate (7/19). Off PPI a reverse ratio shows with an atypical $\mathrm{SI}^{+}$rate of $7 / 21$ and a typical $\mathrm{SI}^{+}$rate of 14/21 (table 1).

\section{Questionnaires}

Of the 32 questionnaires, 6 were not filled out completely. They were excluded from further analysis $\left(\mathrm{PPI}^{+}=\right.$ 2 ; $\left.\mathrm{PPI}^{-}=4\right)$. There were no statistical differences in RDQ score between the $\mathrm{PPI}^{+}$and $\mathrm{PPI}^{-}$group. This was also for analysis of subgroups, made with regard to either positive or negative SI to either typical or atypical symptoms. The mean RDQ score in the $\mathrm{PPI}^{+}$group was $17.8 \pm 10.4(0-$ $33)$ and in the $\mathrm{PPI}^{-}$group $20.1 \pm 9.7(0-34)$. The patients with the lowest RDQ score (0 respectively in both groups) both did not have a pathologic DeMeester score and both had a negative SI. 


\section{Discussion}

MII-pH appears to be a useful tool to investigate patients with symptoms of GERD on and off PPI therapy. These data show the important role of nonacid reflux in patients with GERD symptoms. We found that the discrimination between typical and atypical symptoms and their association to reflux was higher in patients taking no PPI medication. Nonacid reflux was mostly associated with atypical symptoms and acid reflux was more frequently associated to typical symptoms. Our results are in agreement with the data from a recent multicenter trail [1]. The data of this trail underline the association of atypical symptoms to nonacid reflux.

Patients without a pathologic DeMeester score would usually be categorized as 'no reflux disease'. Our data show that even in these patients there was correlation of symptoms to either acid or nonacid reflux. That underlines the use of MII-pH in patients that were uninvestigated before.

There are limitations to MII-pH. Normal values for all parameters acquired during MII-pH are not established. There are significant interindividual differences in nonacid reflux that depend on the individual him/herself. Eating and drinking behavior may have a certain influence on reflux and surely on reflux content. The likelihood of symptom association to reflux episodes is not well expressed with the SI. There are other modalities like the symptom association probability (SAP), which should minimize these limitations [6]. Recent investigations found restrictions also for the SAP if patients report rarely or too frequent about their symptoms [7].

The exact composition of nonacid reflux contents cannot be investigated. MII-pH can only determine whether the reflux contents are liquid, gas or solid. Other modalities like the Bilitec system are able to detect bile reflux $[6,7]$, therefore we believe that a combination of MII-pH and Bilitec would be useful to further investigate the type of gastric refluxates in the esophagus.

Although PPI therapy clearly decreases the esophageal acid exposure, it is already known that PPI therapy has no impact on reflux frequency [8]. In our study the impact on PPI on reflux frequency could not be studied due to study design. There was no difference in RDQ score between patients taking PPI and those without acid-suppressive medication. The RDQ score was independent of acid and nonacid reflux and its correlation to symptoms (SI). In the evaluation of the original RDQ, the presence of nonacid reflux causing symptoms was not considered. The results of this study support the feasibility of the RDQ to acquire information about symptomatic reflux independent of its acidity.

Summarizing, MII-pH is a useful tool to investigate patients with symptoms of GERD on and off PPI therapy. Furthermore, MII-pH provides the opportunity to investigate additional mechanisms of GERD that can potentially lead to new strategies for treatment.

\section{References}

1 Mainie I, Tutuian R, Shay S, Vela M, Zhang X, Sifrim D, Castell D: Acid and non-acid reflux in patients with persistent symptoms despite acid suppressive therapy. A multicentre study using combined ambulatory impedance-pH monitoring. Gut 2006.

$>2$ Silny J: Intraluminal multiple electric impedance procedure for measurement of gastrointestinal motility. J Gastrointest Motil 1991;3:151-162.

-3 Vaezi MF, Shay SS: New techniques in measuring nonacidic esophageal reflux. Semin Thorac Cardiovasc Surg 2001;13:255-264.
-4 Tutuian R, Castell DO: Reflux monitoring: role of combined multichannel intraluminal impedance and $\mathrm{pH}$. Gastrointest Endosc Clin N Am 2005;15:361-371.

$\checkmark 5$ Nocon M, Kulig M, Leodolter A, Malfertheiner P, Willich SN: Validation of the Reflux Disease Questionnaire for a German population. Eur J Gastroenterol Hepatol 2005;17:229-233.

-6 Stein HJ, Kraemer SJ, Feussner H, Siewert JR: Quantifying intestino-esophageal reflux with a fiberoptic bilirubin detection probe (in German). Z Gastroenterol 1994;32:247251.
7 Vaezi MF, Lacamera RG, Richter JE: Validation studies of Bilitec 2000: an ambulatory duodenogastric reflux monitoring system. Am J Physiol 1994;267:G1050-G1057.

$>8$ Tamhankar AP, Peters JH, Portale G, Hsieh CC, Hagen JA, Bremner CG, DeMeester TR: Omeprazole does not reduce gastroesophageal reflux: new insights using multichannel intraluminal impedance technology. J Gastrointest Surg 2004;8:890-897; discussion 897-898. 